\title{
La reforma de las formas de gestión de los servicios públicos locales. La contratación de las sociedades públicas locales
}

\author{
Encarnación Montoya Martín \\ Profesora Titular de Derecho Administrativo
}

SUMARIO: I. CONSIDERACIONES GENERALES. II LOS SERVICIOS PÚBLICOS LOCALES Y SUS MODOS DE GESTIÓN TRAS LA REFORMA DE LA LEY 57/2003: el art. 85.2 LBRL. A) Uniformidad con el modelo estatal. B) Especialidades del régimen de los Organismos autónomos (OA) y Entidades públicas empresariales (EPES) en el ámbito local: el art. 85 bis LBRL. C) La Sociedad mercantil local, cuyo capital social pertenezca íntegramente a la entidad local o a un ente público de la misma (art. 85. ter LBRL). D) La Gestión indirecta: remisión a las distintas formas previstas para el contrato de gestión de servicios públicos en el art. 156 TR de la Ley de Contratos de las Administraciones Públicas, RDL 2/2000, de 16 de junio (TRLACP). E) La reordenación de las sociedades mercantiles locales: Disposición Adicional Duodécima de la LMMGL. III. EL RÉGIMEN DE LA CONTRATACIÓN DE LA SOCIEDAD MERCANTIL LOCAL Y DE LA SOCIEDAD DE ECONOMÍA MIXTA: A) Los contratos de la empresa pública mercantil con terceros: 1. El concepto de Organismo de Derecho público en el Derecho comunitario. 2. La reforma del TRLCAP por el art. 67 de la Ley 62/2003, de 30 de diciembre, de medidas fiscales, administrativas y del orden social. 3. La jurisdicción competente para fiscalizar los requisitos de capacidad, publicidad, procedimientos y formas de adjudicación de los contratos de las sociedades mercantiles públicas. B) Las encomiendas o encargos de la Administración matriz con las empresas públicas mercantiles: Contrato versus consideración de medio propio: 1. Desde la vertiente del ordenamiento jurídico interno. 2. Desde la vertiente del Derecho comunitario: la STJUE de 13 de enero de 2005. C) La modificación del TRLCAP por el Real Decreto Ley 5/2005, de 11 de marzo, de reformas urgentes para el impulso a la productividad y para la mejora de la contratación pública. IV. CONCLUSIONES.

\section{CONSIDERACIONES GENERALES}

La reforma de los servicios locales y sus formas de gestión tiene como presupuesto una definición positiva y actualizada de las competencias locales, en 
línea con la Carta Europea de la Autonomía Local ${ }^{1}$ y las Recomendaciones del Consejo de Europa para su aplicación en España. Así se ha puesto igualmente de manifiesto en el Primer borrador del Libro Blanco para la Reforma del Gobierno Local en España ${ }^{2}$ estos días sometido a intenso debate y discusión.

Dado que en la Constitución la autonomía que se predica de los municipios, provincias y CCAA que se constituyan lo es para la gestión de sus intereses respectivos, y no cabe hablar de gestión de intereses sin que se ostenten las competencias necesarias para ello, debemos concluir que la autonomía local proclamada en nuestra Carta Magna presupone un contenido competencial sobre el que proyectarse. El problema deriva de que la autonomía local se ha desarrollado en nuestro ordenamiento jurídico centrado en la posición formal de la Administración local respecto de las demás Administraciones, incluso desde una óptica meramente defensiva en virtud de la doctrina de la garantía institucional elaborada por el Tribunal Constitucional, dando lugar a un concepto de autonomía local hoy por hoy notoriamente insuficiente.

Se trata de llenar de contenido positivo las competencias que conforman la autonomía local y evitar la actual remisión en blanco a las leyes sectoriales para determinar discrecionalmente su contenido. El principio de subsidiariedad desarrollado en el Derecho comunitario aparece como un instrumento adecuado en esta tarea. Además urge actualizar la lista de las competencias y servicios locales a los tiempos que vivimos y despojarlos del sabor decimonónico que tienen algunos de los servicios enumerados por ejemplo en art. 86.3 de la Ley 7/1985, de dos de abril, de Bases de Régimen Local (en adelante LBRL) como mataderos. Hay que hacer notar que el propio concepto de servicio público local que maneja la LBRL está necesitado de aggiornamento, dado la era privatizadora y liberalizadora en la que nos encontramos y que ha transformado el concepto clásico subjetivo de servicio público en la noción de servicio universal y en obligaciones de servicio público. Esto conlleva asimismo un cambio en el papel de la Administración local que ha de tener potestades ordenadoras y de control sobre tales actividades cuya satisfacción ha de garantizar en niveles de universalidad, regularidad y calidad.

\footnotetext{
${ }^{1}$ Adoptada por el Comité de Ministros del Consejo de Europa el 27 de junio de 1985 y abierta a la firma de los Estados miembros el 15 de octubre del mismo año. Ha sido ratificada por España el 20 de enero de 1988.
}

${ }^{2}$ Art. 2, apartado 2º, de la Orden APU/2648/2004, de 27 de julio (BOE de 4 de agosto). 


\section{LOS SERVICIOS PÚBLICOS LOCALES Y SUS MODOS DE GES- TIÓN TRAS LA REFORMA DE LA LEY 57/2003: el art. 85.2LBRL}

\section{A) Uniformidad con el modelo estatal.}

La LBRL, modificada por la Ley 57/2003, de 16 de diciembre, de Medidas para la Modernización del Gobierno local (LMMGL), ha supuesto la incorporación a nivel local de la clasificación que de los organismos públicos ha realizado la Ley 6/1997, de 14 de abril, de Organización y Funcionamiento de la Administración General del Estado (en adelante LOFAGE). Esta opción viene a confirmar que el Título III de la LOFAGE debería haber tenido la calificación de legislación básica en virtud del art. 149.1.18CE ${ }^{3}$. En definitiva, la finalidad de la reforma ha sido uniformar las modalidades organizativas instrumentales a imagen y semejanza de la LOFAGE, pero desde perspectivas distintas, pues mientras que la LOFAGE se sitúa en el Título III desde la vertiente de las modalidades de organización de la Administración institucional del Estado, en definitiva, la teoría de la organización, en cambio los arts. 85, 85 bis y 85 ter (tras la LMMGL) se posicionan exclusivamente desde la más estrecha perspectiva de las modalidades de gestión de los servicios públicos ${ }^{4}$. A nuestro juicio este enfoque explica la llamativa ausencia de un concepto de empresa pública local, por contraste con la legislación estatal y autonómica. Esta perspectiva más encorsetada de la normativa local provoca algunas confusiones en particular por lo que se refiere a la necesidad de seguir o no el denominado expediente de municipalización (art. 97 TRRL en todos sus trámites) para todo tipo de actividades, también para la prestación de servicios públicos locales estricto sensu, incluidos los servicios mínimos obligatorios del art. 26 LBRL y los

\footnotetext{
${ }^{3}$ Vid. la STC 14/1986, de 5 de marzo, caso de la "Sociedad pública especial Vasca", una sociedad mercantil nueva y distinta de la SA, regulada en la Ley 12/1983, de 22 de junio, de Principios Ordenadores de la Hacienda General del País Vasco, en la que el TC afirmó: "la regulación que de las sociedades especiales se realiza en la Ley impugnada, posee un notorio carácter público, en cuanto rectora de la actuación de entes de tal naturaleza, merced a la creación de una forma societaria atípica, como instrumento de acción administrativa, lo que en esencia no es otra cosa que incidir en el régimen jurídico de las Administraciones públicas, lo que está reservado en exclusividad al Estado- en cuanto al establecimiento de sus bases- en el art.- 149.1.18 de la CE (...) porque si existe alguna institución cuyo encuadramiento pueda realizarse del modo más absoluto dentro de la amplia rúbrica "régimen de las Administraciones públicas" ésta es precisamente la personificación de tales Administraciones para su constitución, funcionamiento y actuación, en cualquiera de sus posibilidades legales, una de ellas la que aquí se contempla".

${ }^{4}$ Vid. Romero Hernández, F. "Los modos de gestión de los servicios públicos en el Proyecto de Ley de Medidas para la Modernización del Gobierno local (PLMGL)”, Cosital, no ${ }^{2}$ 69, 2003, págs. 15 y ss.
} 
reservados (art. 86.3 LBRL), o sólo para el ejercicio de la iniciativa pública en la economía ${ }^{5}$. El TS ha mantenido criterios dispares, pero más recientemente ha sostenido en la sentencia de 1 de febrero de 2002 (Arz. 1590) que la creación de empresas municipales para la gestión de servicios públicos esenciales exige asimismo un expediente previo para acreditar la oportunidad y conveniencia de la medida. En el pleito se discutía si la creación de una sociedad mercantil municipal, -en el caso la Sociedad Municipal Residuos Sólidos Urbanos, SL-, que tenga por objeto un servicio público local esencial, como sostenía el Ayuntamiento de Marbella, implica ejercer la iniciativa pública para el ejercicio de actividades económicas conforme al art. 128.2 CE y, en consecuencia, exige como presupuesto, la tramitación del expediente acreditativo de la conveniencia y oportunidad de la medida a que se refiere el art. 86.1 LBRL y 97 TRRL $^{6}$.

Esta exportación del régimen estatal a la Administración local lleva aparejado el traslado de las virtudes, pero también de los defectos del régimen de los organismos públicos efectuada por la LOFAGE.

En nuestra opinión, en el haber de la trasposición del modelo estatal se encuentra el criterio de racionalización aportado por la LOFAGE consistente en el establecimiento de una correspondencia entre forma jurídica elegida y

\footnotetext{
${ }^{5}$ Como afirma Del Guayo desde la autonomía local y de acuerdo con las tendencias descentralizadoras "parece conveniente que se reconozca a las EELL su condición de agentes de promoción económica y es necesario destacar que los entes locales puedan desarrollar todo tipo de iniciativas económicas en beneficio de los vecinos. Sin embargo, el ámbito de la libre iniciativa económica está oscurecido en la legislación de régimen local, pues se mezcla con el ámbito de los servicios esenciales reservados o servicios públicos, (...) resulta conveniente seguir clarificando la distinción entre los dos grandes ámbitos de la actividad local, en beneficio, simultáneamente, de ambas perspectivas, porque si se acierta a separar de la categoría de los servicios públicos locales las actividades o servicios económicos propios de la iniciativa local se liberará a estos últimos de ciertas limitaciones que las normas imponen, tanto en la creación como en la gestión de los servicios públicos, y, desde la perspectiva de la libertad de empresa, surgirán igualmente beneficios si se clarifica definitivamente la distinción entre ambas cosas, pues los monopolios y formas asimiladas serán posibilidades abiertas, exclusivamente, en aquellas actividades que sean, en sentido estricto, servicios públicos locales" en "La gestión de servicios públicos locales", $R A P, \mathrm{n}^{\circ}$ 165, 2004, pág.129.

${ }^{6}$ El TS ha afirmado a este respecto: "En el caso examinado, (...) el expediente cuya tramitación exige la Ley no ha existido, como expresamente reconoce el Ayuntamiento. La naturaleza y finalidad de dicho expediente lo convierten en presupuesto procedimental esencial para legitimar la inmisión del poder público en la actividad económica privada, tal como aparece configurado en la Ley de acuerdo con los principios constitucionales. Por ello, (...) la ausencia de expediente previo implica la nulidad de pleno derecho a que se refiere el art. 62.1 e) de la Ley 30/1992".
} 
fin o actividad como límite a la discrecionalidad de la Administración en la elección de los ropajes jurídicos ${ }^{7}$. Así pues a tenor del art. 45.1 LOFAGE la fórmula del Organismo Autónomo (OA) ha de ser utilizada para la realización de actividades de fomento, prestacionales o de gestión de servicios públicos. En cambio, las actividades propias de las Entidades públicas empresariales (EPES) a tenor del art. 53 LOFAGE son la realización de actividades prestacionales, la gestión de servicios o la producción de bienes de interés público susceptibles de contraprestación. A sensu contrario, el OA no puede ser utilizado para actividades de producción bienes o gestión de servicios en régimen de mercado, toda vez que al tratarse de una fórmula de Derecho administrativo no es apta para el ejercicio de la potestad de iniciativa pública en la economía (art. 128.2CE) ${ }^{8}$. Por su parte, las EPES no pueden tener encomendadas actividades administrativas de fomento.

El criterio implantado por la LOFAGE se ha visto completado desde la vertiente presupuestaria por el art. 3 de la Ley 47/2003, de 26 de noviembre, General Presupuestaria que clasifica a las entidades integrantes del sector público según su naturaleza económico-financiera en los siguientes sectores: sector público administrativo, sector público empresarial y el sector público fundacional. A tal efecto, la referida ley establece como características determinantes de la pertenencia al sector empresarial el que la actividad principal consista en la producción de bienes y servicios destinados al consumo individual o colectivo, y que mayoritariamente se financien con ingresos comercia-

\footnotetext{
${ }^{7}$ Vid. Pérez Moreno, A-Montoya Martín, E."Formas jurídicas del sector empresarial del Estado
} en la era de las privatizaciones”, RAAP, nº 39, 2000, págs 53-103.

\footnotetext{
${ }^{8}$ No compartimos el criterio del profesor Mestre Delgado, J.F. cuando afirma que el Organismo autónomo resulta útil no sólo para la prestación de servicios públicos, sino también para el desarrollo de actividades económicas como resultado de la iniciativa pública en la actividad económica, posibilidad que se encontraría limitada sólo por la necesidad de respetar las reglas de la competencia, toda vez que del art. 45 LOFAGE al que reenvía expresamente el art. 85.bis LBRL, no se desprende dicha posibilidad. Además el constituir una fórmula de Derecho Administrativo la convierte en un ropaje poco ágil para actuar en el mercado según las reglas de la competencia y de la igualdad con la empresa privada que impone nuestra CE. A ello se añade que en el ámbito local que aquí nos importa, el art. 85 bis 1.LBRL contempla las modalidades organizativas de los OA y EPES para la gestión directa de los servicios de la competencia local -insisto- remitiendo su régimen jurídico a lo dispuesto en la LOFAGE con las especialidades previstas en el precepto. "Las formas de prestación de los servicios públicos locales tras la Ley 57/2003, de 16 de diciembre, de Medidas para la Modernización del Gobierno local”, iustel.com RGDA, no 7, dic. 2004, pág. 12. Idem en "Las formas de prestación de los servicios públicos locales. En particular, la concesión”, Tratado de Derecho Municipal, AA.VV, Muñoz Machado, S. Director, Civitas, Madrid, $2^{a}$ edic. 2003, Tomo II, pág. 1460.
} 
les, entendiéndose por tales, los ingresos, cualquiera que sea su naturaleza, obtenidos como contrapartida de las entregas de bienes o prestaciones de servi$\operatorname{cios}($ art. 3.1.b).

Asimismo, la LOFAGE ha contribuido a fijar con nitidez los límites de la Administración institucional, quedando extramuros las sociedades mercantiles públicas que, al no ser Administración pública, no pueden disponer de facultades que impliquen ejercicio de autoridad (DA Duodécima LOFAGE). De ahí que con acierto el art. 85.3 LBRL reformado por LMMGL disponga:

"En ningún caso podrán prestarse por gestión indirecta ni mediante sociedad mercantil de capital social exclusivamente local los servicios públicos que impliquen ejercicio de autoridad".

En cambio, en el debe o lista de desaciertos de la LOFAGE se encuentra la significativa ausencia de las fundaciones, cuya omisión se reproduce en el ámbito local, entre las modalidades de gestión de los servicios públicos locales. Hay que tener en cuenta que el art. 3 de la vigente Ley 50/2002, de 26 de diciembre, de Fundaciones contiene una habilitación legal genérica en el art. 8 para que las personas jurídico-públicas constituyan fundaciones, salvo que sus normas reguladoras establezcan lo contrario. Además, el Capítulo XI de la Ley lleva a cabo una regulación específica para las denominadas "Fundaciones del sector público estatal". Por todo ello, ninguna duda cabe de que las Entidades locales pueden crear y participar en fundaciones, cuestión distinta es si pueden ser utilizadas como una modalidad de gestión de los servicios locales. Y, en principio, ninguna objeción se suscita para ello, aunque la legislación local ha de contemplar las especialidades de la utilización de esta fórmula de Derecho privado por la Administración local, en particular su régimen de control.

Centrados en los modos de gestión de los servicios públicos locales la LMMGL se ha caracterizado por su inmovilismo, toda vez que pese a lo que se anuncia en su Exposición de Motivos, el reformado art. 85 LBRL continua con las viejas categorías y no introduce ni una sola referencia a los conceptos de servicios de interés general, servicio universal, servicios de interés económico general $\mathrm{u}$ obligaciones de servicio público. Como ha señalado con acierto MARTÍNEZ PALLARÉS ${ }^{9}$ las razones del inmovilismo del legislador estatal

\footnotetext{
${ }^{9}$ Martínez Pallarés, PL. "Los servicios públicos locales en la Ley 57/2003, de 16 de diciembre, de medidas para la modernización del gobierno local. Especial referencia a su incidencia en la legislación de Administración local de Aragón”, Revista Aragonesa de Administración Pública, no 24, 2004 pág. 299.
} 
pueden responder a la conversión de un texto legal inicialmente previsto para la reforma organizativa de los municipios de gran población en una reforma de más amplia incidencia, si bien de manera sobrevenida. En efecto, el art. 85 LBRL en su nueva redacción dispone:

"1.Son servicios públicos locales los que prestan las entidades locales en el ámbito de sus competencias.

2. Los servicios públicos de la competencia local podrán gestionarse mediante alguna de las siguientes formas:

A) Gestión directa:

a) Gestión por la propia entidad local.

b) Organismo autónomo local.

c) Entidad pública empresarial local.

d) Sociedad mercantil local, cuyo capital pertenezca íntegramente a la entidad local o a un ente público de la misma.

B) Gestión indirecta, mediante las distintas formas previstas para el contrato de gestión de servicios públicos en el art. 156 del Texto Refundido de la Ley de Contratos de las Administraciones Públicas, aprobado por Real Decreto Legislativo 2/2000, de 16 de junio".

B) Especialidades del régimen de los Organismos autónomos (OA) y Entidades públicas empresariales (EPES)en el ámbito local: el art. 85 bis LBRL.

La creación, modificación, refundición y supresión corresponderá al Pleno de la Entidad local, que aprobará sus estatutos. Hay que recordar que el proceso de creación de un organismo público en la LOFAGE pasa por dos momentos diferenciados: acuerdo de creación y aprobación de sus estatutos. Ambos momentos se distinguen en el art. 61 LOFAGE sobre la base de la Ley de creación del organismo y los estatutos que son aprobados por Decreto del Consejo de Ministros. Lógicamente este planteamiento vertebrado sobre la iniciativa legislativa del Gobierno no puede trasladarse sin más a la esfera local. En el ámbito local la competencia corresponde al Pleno que la ejerce a través de un acuerdo normativa de constitución que deberá contener como mínimo: 
- expresión del tipo de organismo que se crea, Organismo Autónomo o entidad pública empresarial;

- indicación del área de actividad encomendada y sus finalidades generales, cumpliendo estrictamente con el principio de especialidad;

- indicación de la Concejalía u órgano equivalente de la corporación local u organismo de adscripción. Al órgano u organismo de adscripción corresponde: ejercer los controles específicos sobre la evolución de los gastos de personal y de la gestión de sus recursos humanos; autorización para celebrar contratos de cuantía superior a las cantidades previamente fijadas y control de eficacia;

- establecimiento de los objetivos que la entidad ha de alcanzar en el área de actividad encomendada, acompañada de una estimación de los recursos humanos, financieros y materiales precisos para su funcionamiento.

En un segundo momento, que puede darse conjunta o sucesivamente, deberá procederse a la aprobación expresa de los correspondientes estatutos, con el contenido mínimo que proclama el art. 85.2 bis LBRL:

- Determinación de los máximos órganos de dirección, ya sean unipersonales o colegiados, forma de designación e indicación de aquellos cuyas resoluciones agotan la vía administrativa. El titular de los máximos órganos de gobierno ha de ser funcionario de carrera o laboral de las Administraciones públicas o un profesional del sector privado, titulados superiores en ambos casos y con más de 5 años de ejercicio en el segundo ${ }^{10}$. En los municipios de gran población tendrán la consideración de órganos directivos (art. 130.2 LBRL). Por ende, están sujetos al régimen de incompatibilidades del personal al servicio de las Administraciones públicas y al resto de las normas que resulten de aplicación (art. 130.4 LBRL).

En los OA deberá existir un Consejo rector, cuya composición se determinará en sus estatutos.

En las EPES deberá existir un Consejo de Administración cuya composición se determinará en sus estatutos. El secretario del Consejo de Administración deberá ser un funcionario público al que se exija para su ingreso titula-

\footnotetext{
${ }^{10}$ La norma no especifica la necesidad de vinculación material entre la actividad desarrollada y el objeto del OA en el que se pretende integrar, lo que suscita lógicamente algunas dificultades aplicativas y de control.
} 
ción superior, ejercerá las funciones de fe pública y asesoramiento legal de los órganos unipersonales y colegiados de estas entidades.

- Funciones y competencias, con indicación de las potestades administrativas generales que ésta puede ejercitar. En caso de las EPES, órganos a los que se confiera el ejercicio de potestades administrativas. A este respecto hay que tener en cuenta que el régimen del personal de las EPES por remisión a la LOFAGE, art. 55 es personal laboral y con carácter excepcional personal funcionario. Si el régimen general de su personal es el propio del Derecho laboral se plantea el problema del ejercicio de funciones públicas que las EPES tengan atribuidas por dicho personal laboral, sobre todo, su confrontación con el art. 92.2 LBRL en interpretación dada por la STC 37/2002, de 14 de febrero ${ }^{11}$.

${ }^{11}$ STC 37/2002, de 14 de febrero, cuestiones de inconstitucionalidad acumuladas contra el art. 92.2. LBRL y preceptos de la Ley 17/1985 de la Función pública de Cataluña. En el F.J. 5 el TC afirma la opción de la Constitución en los arts. 103.3 y 149.1 .18 por el régimen estatutario de los servidores públicos bajo la garantía formal de la reserva de ley, garantía que no excluye el reglamento ejecutivo.

El art. 92.2 LBRL dispone: "Son funciones públicas, cuyo cumplimiento queda reservado exclusivamente al personal sujeto al estatuto funcionarial, las que impliquen ejercicio de autoridad, las de fe pública y asesoramiento legal preceptivo, las de control y fiscalización interna de la gestión económico-financiera y presupuestaria, las de contabilidad y tesorería y, en general, aquellas que, en desarrollo de la presente Ley, se reserven a los funcionarios para mejor garantía de la objetividad, imparcialidad e independencia en el ejercicio de la función”. La Sala que plantea la cuestión de inconstitucionalidad se centra en el inciso final al considerar que puede ser contrario a la reserva de ley del art. 103.3CE, en cuanto comprensiva, entre otros aspectos del estatuto funcionarial, de los modos de provisión de los puestos de trabajo al servicio de las Administraciones públicas. Considera la Sala que aquí el legislador ha incumplido su función irrenunciable al efectuar en esta materia un apoderamiento a la facultad reglamentaria que excede de los límites permitidos por aquella.

La técnica en cambio del art. 15 de la Ley 30/1984 modificada es la inversa, porque tasa precisamente los puestos que pueden ser ocupados por personal laboral, reservándose todos los demás a personal funcionario. Recuérdese que la versión originaria del art. 15.1 Ley 30/1984, 2 de agosto, encomendaba al Ministerio de la Presidencia determinar los requisitos para el desempeño de cada puesto de trabajo, "debiendo especificarse aquellos puestos que, en atención a la naturaleza de su contenido, se reservan a funcionarios públicos” se declaró inconstitucional por STC 99/87, al considerar en razón del ámbito objetivo de la reserva de Ley del art. 103.3CE que sólo a la Ley corresponde la regulación del modo de provisión de los puestos de trabajo al servicio de las Administraciones públicas. Esto se desprende de la CE, y de la consiguiente exigencia de que las normas que permitan excepcionar tal previsión constitucional sean dispuestas por el legislador, garantizándose una efectiva sujeción de los órganos administrativos, a la hora de decidir qué puestos concretos de trabajo pueden ser cubiertos por quienes no posean la condición de funcionario.

En el F.J 6 de la meritada Sentencia 37/2002 el TC examina el art. 92.2LBRL a la luz de la doctrina expuesta. En efecto, el precepto enumera las funciones que están reservadas a funcionarios, 
- Patrimonio que se les asigne para el cumplimiento de sus fines y recursos económicos que hayan de financiar el organismo.

- Régimen relativo a recursos humanos, patrimonio y contratación.

- Régimen presupuestario, económico-financiero, contabilidad de intervención, control financiero y control de eficacia, que será en todo caso conformes con la legislación de Haciendas Locales y con lo dispuesto en el Capítulo III Título X de esta Ley ${ }^{12}$.

Finalmente, los estatutos deberán ser aprobados y publicados con carácter previo a la entrada en funcionamiento efectivo del organismo público correspondiente (art. 85.bis.3LBRL).

Por su parte, la Disposición Transitoria Tercera de la Ley 57/2003 manda que en el plazo de 6 meses desde su entrada en vigor los plenos de los ayuntamientos deberán adecuar los organismos autónomos y adaptar sus estatutos al régimen del art. 85.bis LBRL. Este mandato de adaptación, por cierto al día de hoy, incumplido de manera generalizada por las Entidades locales, implica:

- adecuación de los actuales organismos autónomos administrativos al organismo autónomo local previsto en la ley, pues la LOFAGE ha suprimido la clasificación de los OA en administrativos y comerciales, industriales, financieros o análogos que proviene de la Ley General Presupuestaria de 4 de enero de 1977.

y que son las funciones públicas necesarias en todas las corporaciones locales, cuya responsabilidad administrativa está reservada a funcionarios con habilitación de carácter nacional. El TC no considera inconstitucional el art. 92.2LBRL pues afirma que en su totalidad y no aislado el precepto contiene una determinación material que sería, por sí suficiente, de las funciones que han de ser ejercidas por funcionarios públicos y, a sensu contrario, de las que no pueden ser encomendadas al personal contratado, el cual no podrá ocupar aquellos puestos de trabajo que impliquen el ejercicio de las funciones enumeradas en el primer inciso del art. 92.2, esto es, las que impliquen ejercicio de autoridad y las clasificadas como necesarias en todas las corporaciones locales, ni las que se exijan para mejor garantía de objetividad, imparcialidad e independencia en el ejercicio de función pública.

${ }^{12}$ El Texto Refundido de la Ley de Haciendas Locales aprobado por Real Decreto Legislativo 23/2004, de 5 de marzo, todavía no ha incluido a las EPES, por lo que ha de estarse a lo dispuesto en la Disposición Transitoria Segunda de la Ley 57/2003, de 16 de noviembre, que establece: "En tanto no se modifique la Ley 39/1988, de 28 de diciembre, Reguladora de las Haciendas Locales, en las materias previstas en el art. 85 bis, apartado segundo, párrafo f de la Ley 7/1985, de 2 de abril, Reguladora de las Bases de Régimen Local, será de aplicación a las entidades públicas empresariales lo dispuesto en la citada Ley 39/1988 en referencia a las sociedades mercantiles locales cuyo capital pertenezca íntegramente a las entidades locales". 
- adecuación de los actuales organismos autónomos comerciales industriales financieros o análogos a la fórmula del OA o EPES regulado en el art. 85 bis LBRL.

Por cierto que, aunque no lo prevé expresamente así la Ley, del nuevo art. 85.3 LBRL se desprende con toda claridad que las sociedades mercantiles locales que a la entrada en vigor de la LMMGL ejercen de forma puntual funciones de autoridad deberán adaptarse a la fórmula de la EPES siempre y cuando se quieran mantener las correspondientes potestades y prerrogativas públicas. De ahí la necesidad de haber previsto expresamente este supuesto por el legislador a efectos de conceder el oportuno plazo para la correspondiente adaptación.

C) La Sociedad mercantil local, cuyo capital social pertenezca íntegramente a la entidad local o a un ente público de la misma (art. 85. ter LBRL).

Desde la perspectiva terminológica ahora recibe en sentido estricto el nombre de sociedad mercantil local aquella compañía mercantil de responsabilidad limitada ${ }^{13}$ participada en exclusiva de manera directa o indirecta por la entidad local y que se configura como un modo de gestión directa de los servicios públicos locales.

El art 85 ter LBRL introducido por LMMGL establece:

"1. Las sociedades mercantiles locales se regirán íntegramente, cualquiera que sea su forma jurídica, por el ordenamiento jurídico privado, salvo las materias en que les sea de aplicación la normativa presupuestaria, contable, de control financiero, de control de eficacia y contratación, y sin perjuicio de lo señalado en el apartado siguiente de este artículo.

2. La sociedad deberá adoptar una de las formas de sociedad mercantil de responsabilidad limitada, y en la escritura de constitución constará el capital, que deberá ser aportado íntegramente por la entidad local o un ente público de la misma.

3. Los estatutos determinarán la forma de designación y el funcionamiento de la Junta General y del Consejo de Administración, así como los máximos órganos de dirección de la misma”.

${ }^{13}$ Entre las sociedades mercantiles de responsabilidad limitada queda excluida la Sociedad limitada Nueva Empresa, regulada por la Ley 7/2003, de 1 de abril, pues esta fórmula limita la posibilidad de ser socio sólo a las personas físicas. 
El art. 85 ter viene a transcribir casi literalmente la Disposición Adicional 12 de LOFAGE, en la redacción dada por la Disposición Final Primera de la Ley 33/2003, de 3 de noviembre, de Patrimonio de las Administraciones Públicas (LPAP) pero hay algunas diferencias dignas de notar:

- el art. 85 ter añade a la normativa pública el control de eficacia, lo que no significa que antes no estuviesen sujetas a este control en virtud de los arts. 220 y 221 TR Ley de Haciendas Locales (TRLHL) referidos a todas las sociedades dependientes de las Entidades Locales.

- en cambio, el art. 85 ter olvida toda referencia a la normativa patrimonial pública contenida en la LPAP. Esta Ley trata de crear una peculiar especie de SA de capital íntegramente público estatal a las que la Ley reconduce al ámbito público por mor del art. 166.2 y del Título VII. Empero, hay que notar que el referido Título VII no es básico y sólo es aplicable a la Administración General del Estado. Mas no hay que olvidar que en la LPAP sí hay preceptos básicos como los principios aplicables a los bienes y derechos patrimoniales que enumera el art. 8, toda vez que los títulos representativos de capital en sociedades mercantiles son bienes patrimoniales ${ }^{14}$.

Con todo, las novedades más significativas que aporta el art. 85 ter son:

-posibilidad de que las sociedades mercantiles locales se constituyan con capital aportado por un OA o EPES local, es decir, se incorpora la participación exclusiva indirecta de la Entidad local;

-remisión a los estatutos para la configuración de la forma de designación y funcionamiento de los órganos de la entidad, con lo que el precepto parece acabar con la especialidad orgánica más característica de la sociedades mercantiles de capital exclusivo local (en la terminología tradicional sociedad privada municipal): que el Pleno de la Corporación se constituya en Junta general de la compañía, que a su vez designa el Consejo de Administración (arts. 90 a 94 del Reglamento de Servicios de las Corporaciones locales de 17 de junio de 1955). Estimo que en el caso de la participación exclusiva directa en la sociedad mercantil local por parte de la Administración municipal continua rigiendo dicha especialidad organizativa. Abogar por su mantenimiento refuerza y subraya la proximidad de la dependencia entre la sociedad mercantil

${ }^{14}$ Vid. Arts. 76 TRRL y 6 del Reglamento de Bienes de las Entidades Locales, aprobado por Real Decreto 1372/1986, de 13 de junio. 
local como puro ente instrumental en manos de la Administración municipal. Sólo cuando la sociedad mercantil local está participada íntegramente por un OA o EPES se justifica la derogación de dicha especialidad.

-prohibición expresa de desempeñar funciones de autoridad a tenor del art. 85.3 LBRL. Como ya se ha visto, este precepto hay que ponerlo en relación con el art. 92.2 LBRL que produce la identificación del ejercicio de funciones públicas y el ejercicio de autoridad con reserva de su cumplimiento al personal sujeto a estatuto funcionarial. El art. 85.3 LBRL conlleva la necesidad de aclarar la situación de determinadas sociedades de capital exclusivo local que realizan por ejemplo la gestión del sistema tributario, utilizando fórmulas de dudosa legalidad por medio del artificio técnico de considerar a la empresa como un ente de cooperación del tesorero en el ejercicio de sus funciones públicas; o actos de inspección en el caso de sociedades municipales de abastecimiento de aguas; o resolución de expedientes de desahucio administrativo en caso de sociedades promotoras de viviendas sociales; o, actividad subvencional llevada a cabo por las numerosas sociedades de desarrollo local.

Finalmente, hubiera sido conveniente establecer para las sociedades mercantiles locales en el art. 85.ter la exigencia de la aprobación y publicación de sus estatutos (BOP) con carácter previo al inicio de su funcionamiento efectivo como así se prevé por el art. 85.bis.3LBRL para los OA y las EPES.

D) Gestión indirecta: remisión a las distintas formas previstas para el contrato de gestión de servicios públicos en el art. 156 TR de la Ley de Contratos de las Administraciones Públicas, RDL 2/2000, de 16 de junio (TRLACP).

Se trata de una remisión coherente dado que en dicho precepto se prevén las modalidades de contratación, es decir, los casos que caen bajo la órbita de los contratos, entre ellos las sociedades de economía mixta.

Si alguna duda había durante la redacción originaria art. 85 LBRL sobre la posibilidad de formas de gestión indirecta distintas de las enumeradas, se han despejado. Ahora las modalidades que pueden utilizarse son sólo las recogidas en art. 156 TRLCAP, dado su carácter básico. Por lo que se ha suprimido el arrendamiento como forma de gestión indirecta de los servicios públicos locales, sin perjuicio de que las normas vigentes sobre esta antigua forma de gestión sigan siendo aplicables para los arrendamientos que tengan contratados las Entidades Locales a la fecha de entrada en vigor de la LMMGL. 
E) La reordenación de las sociedades mercantiles locales: Disposición Adicional Duodécima de la LMMGL.

Se trata de una previsión inspirada en el art. 168 LPAP, sobre reestructuración del sector público empresarial del Estado, y que deriva a su vez, de las contenidas en la Ley 7/2001, de 14 de mayo, que introdujo un art. 104 bis en LPE hoy derogada, relativo a la reestructuración de empresas en el seno de la Sociedad Estatal de Participaciones Industriales (SEPI).

Curioso es que en el ámbito local la enmienda $n^{\circ} 160$ que propuso su inclusión en LMMGL contemplaba la figura de las EPES locales sólo para municipios de gran población, y el régimen de reorganización empresarial también sólo para estos municipios. Dicha enmienda disponía: "En el caso de que los municipios de gran población pretendan, en el marco de la modernización y racionalización de su sector público empresarial para coordinar las sociedades mercantiles, municipales o mixtas, debe establecerse una previsión que facilite el procedimiento de transferencia de las participaciones accionariales a la entidad empresarial".

En cambio, la redacción resultante en la DA Duodécima es aplicable a todos los municipios sin distinción, lo cual podría considerarse en parte en contradicción con la filosofía que inspira LMMGL de establecer regímenes municipales distintos en función del tamaño de municipios.

\section{EL RÉGIMEN DE LA CONTRATACIÓN DE LA SOCIEDAD MER- CANTIL LOCAL Y DE LA SOCIEDAD DE ECONOMÍA MIXTA}

En el régimen jurídico de la contratación de las sociedades mercantiles públicas hay que diferenciar de una parte, el régimen de los contratos de dichas sociedades con terceros, y de otra parte, el régimen propio de las relaciones entre la sociedad mercantil y la Administración pública matriz que participa en ellas como socio.

A) Los contratos de la empresa pública mercantil con terceros.

Las relaciones contractuales de las sociedades mercantiles públicas locales (sociedad mercantil local y empresa mixta mayoritariamente pública) ad extra se regulaban por la DA Sexta TRLCAP que establecía:

"Las sociedades mercantiles en cuyo capital sea mayoritaria la participación directa o indirecta de las Administraciones públicas o de sus Organismos 
autónomos, o Entidades de Derecho público, se ajustarán en su actividad contractual a los principios de publicidad y concurrencia, salvo que la naturaleza de la operación a realizar sea incompatible con estos principios”.

Por su parte, el art. 1.3 TRLCAP relativo al ámbito de aplicación subjetivo de la Ley ordena:

"Deberán asimismo ajustar su actividad contractual a la presente Ley los organismos autónomos en todo caso y las restantes entidades de derecho público con personalidad jurídica propia, vinculados o dependientes de cualquiera de las Administraciones públicas, siempre que en aquéllas se den los siguientes requisitos:

a) Que hayan sido creadas para satisfacer específicamente necesidades de interés general que no tengan carácter industrial o mercantil.

b) Que se trate de entidades cuya actividad esté mayoritariamente financiada por las Administraciones públicas u otras entidades de derecho público, o bien, cuya gestión se halle sometida a un control por parte de estas últimas, o cuyos órganos de administración, de dirección o de vigilancia estén compuestos por miembros más de la mitad de los cuales sean nombrados por las Administraciones públicas y otras entidades de derecho público”.

El concepto de Entidades de Derecho público utilizado en el TRLCAP ha de reinterpretarse adecuándolo a la noción de Organismo de Derecho público propio de la normativa comunitaria de la contratación pública. nitario:

1. El concepto de Organismo de Derecho público en el Derecho comu-

Hay que tener en cuenta la vigente Directiva 2004/18/CE, del Parlamento Europeo y del Consejo, de 31 de marzo, sobre coordinación de los procedimientos de adjudicación de los contratos públicos de obras, de suministro y servicios y el concepto de organismo de Derecho público como poder adjudicador que se define sobre la base de los siguientes requisitos: a) que haya sido creado para satisfacer específicamente necesidades de interés general que no tengan carácter industrial o mercantil; b) dotado de personalidad jurídica y c) cuya actividad esté mayoritariamente financiada por el Estado, los entes públicos territoriales u otros organismos de Derecho público, cuya gestión se halle sometida a un control por parte de éstos últimos, o cuyo órgano de administración, de dirección o de vigilancia está compuesto por miembros de los 
cuales más de la mitad sean nombrados por el Estado, los entes públicos territoriales u otros organismos de Derecho público.

La jurisprudencia del Tribunal de Justicia de la Unión Europea ha ido aquilatando la noción de Organismo de Derecho público afirmando que se trata de un concepto comunitario, del que es indiferente la fórmula jurídica de Derecho público o de Derecho privado al que esté sujeto el organismo. Asimismo, basta que una parte de su actividad sea de interés general que no tenga carácter industrial o mercantil para que se aplique en bloque a todo su objeto social la normativa de la contratación pública. Como criterios indiciarios de la naturaleza mercantil o industrial de la actividad se encuentran el ánimo de lucro, el que la actividad se desenvuelva en régimen de mercado y que otros empresarios privados desempeñen la misma actividad. Con todo, el criterio determinante del carácter mercantil o industrial de la actividad es la asunción del propio riesgo en la gestión empresarial, y con ello, la imposibilidad de enjugar las pérdidas por los presupuestos de ninguna Administración ${ }^{15}$.

Con este bagaje sólidamente asentado por el Tribunal de Luxemburgo, era un hecho que la letra del TRLCAP no se acomodaba a la norma y ni a los criterios comunitarios de la contratación pública. Esta situación ampliamente denunciada por la doctrina se ha visto confirmada por las recientes sentencias condenatorias de España por el Tribunal de Justicia.

- La STJUE de 16 de octubre de 2003 Comisión contra R. de España, resuelve el recurso que tiene por objeto que se declare que, con ocasión de la licitación relativa a la ejecución de las obras del Centro Educativo Penitenciaria Experimental de Segovia, convocada por la Sociedad Estatal de Infraestructuras y Equipamientos Penitenciarios, SA (SIEPSA) el Reino de España ha incumplido las obligaciones que le incumben en virtud de la Directiva de contratos públicos de obra. Según el TJ:

"Ha quedado acreditado que SIEPSA se creó específicamente para asumir, exclusivamente, la ejecución de programas y actuaciones previstos en el Plan de Amortización y Creación de Centros Penitenciarios, a efectos de la aplicación de la política penitencia del Estado. Con este fin realiza, según se desprende de sus Estatutos, todas las actividades que resulten necesarias a

\footnotetext{
${ }^{15}$ Véase Montoya Martín, E. "La reciente jurisprudencia del Tribunal de Justicia de la Unión Europea acerca del concepto de "Poder adjudicador" en las Directivas de la contratación pública de servicios, suministros y obras”, RAAP, nº 41, 2001, págs.121-154, y la doctrina allí citada.
} 
efectos de la construcción, gestión, y liquidación del patrimonio penitenciario del Estado" (Cdo 84).

"Por tanto, las necesidades de interés general que SIEPSA se encarga de satisfacer están intrínsecamente vinculadas al orden público, al constituir una condición necesaria para ejercer el poder represivo del Estado" (Cdo 85).

Así pues, actividades como la amortización y creación de centros penitenciarios, que figura entre los principales objetivos de SIEPSA, no están sujetas a la competencia en el mercado. Por consiguiente, dicha sociedad no puede ser considerada como un organismo que ofrezca bienes y servicios en el mercado libre, en competencia con otros operadores económicos, por lo que constituye un Organismo de Derecho público a efectos de la contratación pública.

-La STJUE de 15 de mayo de 2003 Comisión contra Reino de España, asunto 214/00, declara que España ha incumplido las obligaciones que le incumben en virtud de la Directiva 89/665/CEE del Consejo de 21 de diciembre, relativa a la coordinación de las disposiciones legales, reglamentarias y administrativas referentes a la aplicación de los procedimientos de recurso en materia de adjudicación de contratos públicos de suministros y obras, cuyas reglas son también aplicables a los contratos de servicios por previsión expresa del art. 41 de la Directiva 92/50/CEE, de 18 de junio, relativa a tales contratos.

En esta sentencia se aborda una vez más el ámbito subjetivo de las Directivas de la contratación pública, toda vez que la Directiva de recurso define su ámbito material por referencia a éstas y al concepto de entidad adjudicadora y organismo de Derecho público. En definitiva, la primera cuestión de fondo se refiere a la adaptación del Derecho interno en lo relativo al ámbito de aplicación personal de la Directiva 89/665. A tal efecto el TJ afirma una vez más que ha quedado acreditado que en virtud de los arts. 1.3 y DA Sexta del TRLCAP los organismos públicos que tienen estatuto de Derecho privado, categoría constituida en Derecho español por las sociedades mercantiles bajo control público, quedan fuera del ámbito de aplicación personal de la normativa española sobre procedimientos de adjudicación de los contratos públicos, y por tanto, del régimen de recursos en materia de contratación pública.

El TJUE declara una vez más que no cabe interpretar el concepto de organismo de Derecho público en el sentido de que los Estados pueden excluir de antemano a las sociedades mercantiles bajo control público del ámbito de aplicación personal de estas Directivas, y en consecuencia de la Directiva 
89/665. La normativa española en la medida en que excluye del ámbito personal de aplicación de la Directiva 89/665 a las sociedades de Derecho privado, no incorpora correctamente el concepto de entidad adjudicadora. En conclusión, el TJ condena a España por no haber extendido el sistema de recursos garantizados en dicha Directiva a las decisiones adoptadas por las sociedades de Derecho privado que cumplan los tres requisitos exigidos para tener la consideración de Organismo de Derecho público; b) al someter por regla general la posibilidad de que se tomen medidas cautelares en relación con decisiones adoptadas por las entidades adjudicadoras a la necesidad de interponer previamente un recurso contra la decisión de la entidad adjudicadora.

2. La reforma del TRLCAP por el art. 67 de la Ley 62/2003, de 30 de diciembre, de medidas fiscales administrativas y del orden social.

Las precedentes sentencias condenatorias han motivado la reforma puntual del TRLCAP. Así la nueva redacción del art. 2.1 reza como sigue:

"Las entidades de Derecho público no comprendidas en el ámbito definido en el artículo anterior y las sociedades de derecho privado creadas para satisfacer específicamente necesidades de interés general que no tengan carácter industrial o mercantil, siempre que, además, concurra alguno de los requisitos contenidos en el párrafo b) del apartado 3 del artículo anterior quedarán sujetas a las prescripciones de esta ley relativas a la capacidad de las empresas, publicidad, procedimientos de licitación y formas de adjudicación para los contratos de obras, suministros, consultoría y asistencia y servicios de cuantía igual o superior, con exclusión del impuesto sobre el Valor Añadido de 6.242.028 euros (equivalente a 5.000.000 derechos especiales de giro), si se trata de contratos de obras, o a 249.681 euros (equivalente a 200.000 derechos especiales de giro), si se trata de cualquier otro contrato de los mencionados".

Por su parte, se ha modificado igualmente la letra de la DA Sexta de la Ley en los términos siguientes:

"Las sociedades a que se refiere el apartado 1 del artículo 2, para los contratos no comprendidos en el mismo, ajustarán su actividad contractual a los principios de publicidad y concurrencia, salvo que la naturaleza de la operación a realizar sea incompatible con estos principios”.

De lo que se infiere que en el art. 2 bajo la rúbrica de adjudicación de determinados contratos de Derecho privado se consagra para las sociedades mercantiles públicas que constituyan poderes adjudicadores la teoría de los actos 
separables, quedando sometidas al TRLCAP en lo relativo a la publicidad, capacidad de las empresas, publicidad, procedimientos y formas de adjudicación, para los contratos citados, que resultan ser los contratos administrativos típicos según el propio TRLCAP siempre que alcancen las cuantías que señala el precepto. Para el resto de los contratos que celebren las sociedades mercantiles públicas que constituyan Organismo de Derecho público por mor de la DA Sexta, no se aplica ni siquiera la teoría de los actos separables de la legislación de contratos.

3. La jurisdicción competente para fiscalizar los requisitos de capacidad, publicidad, procedimientos y formas de adjudicación de los contratos de las sociedades mercantiles públicas.

El Derecho positivo no lo resolvía expresamente, toda vez que el art. 2.b de la Ley 29/1998, de 13 de julio, de la Jurisdicción contencioso-administrativa (LJCA) dispone que este orden jurisdiccional conocerá de las cuestiones que se susciten en relación con los contratos administrativos y los actos de preparación y adjudicación de los demás contratos sujetos a la legislación de contratación de las Administraciones públicas.

Mas el art. 67.Cuatro de la Ley 62/2003 ha añadido al TRLCAP una DA Décimo Sexta que bajo la rúbrica Recursos en materia de contratos de las sociedades sujetas a esta ley ordena:

"A efectos de reclamaciones y recursos en relación con los contratos a que se refiere el apartado 1 del art. 2 de esta Ley se tendrá en cuenta lo dispuesto en el art. 51 de la Ley 48/1998, de 30 de diciembre, sobre procedimientos de contratación de los sectores excluidos".

Es decir, se atribuye la competencia a la jurisdicción contencioso administrativa, ampliándose el ámbito de la LJCA. En cambio, el conocimiento de los restantes contratos celebrados por estas mismas sociedades, no se olvide, en cuanto poderes adjudicadores, corresponde a la jurisdicción ordinaria, sistema de dualidad de jurisdicciones que estimo, crea confusión.

B. Las encomiendas o encargos de la Administración matriz con las empresas públicas mercantiles: Contrato versus consideración de medio propio.

Respecto a las relaciones entre Administración pública y sus sociedades mercantiles la cuestión que hay que resolver es si en este caso la adjudicación de proyectos, obras, servicios que constituyan su objeto ha de someterse a los 
procedimientos públicos de licitación regulados por el TRLCAP y el Derecho comunitario de la contratación pública. Esta cuestión, que suscita posturas encontradas entre la doctrina ${ }^{16}$ ha de recibir respuesta en función no sólo de nuestro Derecho interno, sino también de los imperativos del Derecho comunitario, así como en función del tipo de contrato o encargo de ejecución que se encomiende. Nos referimos a lo que en la jerga comunitaria se conoce como los "contratos in house".

\section{Desde la vertiente del ordenamiento jurídico interno.}

Respecto a las relaciones entre Administración pública y sus sociedades mercantiles la cuestión que hay que resolver es si en este caso la encomienda o encargos ${ }^{17}$ han de someterse a los procedimientos públicos de licitación re-

\footnotetext{
${ }^{16}$ Carbonell Porras, E. "Título jurídico que habilita el ejercicio de la actividad de las sociedades mercantiles estatales de infraestructura viaria ¿Convenio o contrato administrativo?”, Estudios de Derecho Público Económico. Libro Homenaje al Prof. Dr. D. Sebastián Martín-Retortillo, AA.VV. Coordinador Cosculluela Montaner, L., Civitas, Madrid, 2003. págs. 377-394, mantiene una postura restrictiva según la cual las Administraciones públicas no pueden atribuir a sociedades mercantiles públicas la ejecución directa de obras o la construcción y explotación de una obra por encima del umbral comunitario sin respetar los principios de publicidad y concurrencia previstos en el Derecho comunitario. Y por debajo de dicho umbral, entra en aplicación el art. 3.1.d) TRLCAP, se trataría de un convenio prohibido toda vez que su objeto sería el propio de un contrato administrativo. Las sociedades públicas de infraestructura pueden concurrir a los procedimientos de selección de los concesionarios de obras públicas, conforme a las reglas generales que regulan este contrato administrativo. Quiere decirse que, salvo en el caso del contrato de servicios, donde la propia Directiva 92/50/CEE, excluye su aplicación a las prestaciones encomendadas a las empresas públicas siempre que no se violen otras reglas comunitarias. El resto de los contratos han de someterse a los procedimientos públicos de licitación. No obstante, entiendo que dicha opinión sumamente restrictiva se ha visto afectada por la reciente STJU de 13 de enero de 2005.

${ }^{17}$ Véase como ejemplo, la Ley 10/1998, de 28 de diciembre, del Presupuestos de la Comunidad autónoma de Andalucía para 1999 cuyo art. 19 regula el régimen de financiación de la actividad de las empresas de la Junta de Andalucía con cargo a aportaciones de la propia Junta de Andalucía y sus Organismos autónomos, distinguiéndose entre las aportaciones para financiar la gestión de las empresas, que se efectuarán mediante subvenciones de explotación y de capital, de acuerdo con el art. 57 de la Ley General de Hacienda Pública de la Comunidad Autónoma de Andalucía, y los casos de gestión de las actuaciones de competencia de las Consejerías u Organismos autónomos de la Junta de Andalucía, que serán financiados con cargo a los créditos establecidos en las distintas secciones presupuestarias y se formalizarán a través de encargos de ejecución. Se pretende así -según manifiesta la Exposición de Motivos de la Ley- un tratamiento uniforme a las distintas situaciones derivadas. En efecto, el art. 19 Tres introduce la figura de los denominados "encargos de gestión" al disponer: "Sin perjuicio de lo establecido en el apartado anterior y lo dispuesto en sus normas específicas, las empresas de la Junta de Andalucía, en el marco de sus estatutos y objeto social, podrán gestionar actuaciones de competencia de las Consejerías u Organismos Autónomos de la Junta de Andalucía, que serán financiados con cargo a los créditos establecidos en las distintas secciones presupuestarias".
} 
gulados por el TRLCAP cuando se califica de medio propio o instrumental. Pese a gozar de personalidad jurídica diferenciada, y centrados en el ámbito local, la sociedad mercantil local, que constituye un modo directo de gestión, no puede considerarse un tercero a efectos de la Administración local matriz, sino una simple opción organizatoria no desvinculada de la organización de la propia Entidad local. De ahí que no tenga sentido que si una Entidad local crea una sociedad mercantil pública para la gestión de competencias, funciones o servicios municipales se le imponga que se someta a la legislación de contratos toda vez que ha creado una organización ad hoc para ello. En otras palabras, se trata de un medio propio de la Administración ${ }^{18}$, calificación que con creciente frecuencia se encuentra en el Derecho positivo ${ }^{19}$.

18 Sosa Wagner, F. La gestión de los servicios públicos locales, Thomson-Civitas, $6^{\mathbf{a}}$ edic. Madrid, 2004, págs. 167-174. Véase el interesante trabajo de Ortiz Mallol, J. "La relación de dependencia de las entidades instrumentales de la Administración pública: algunas notas", RAP, nº 163, 2004, págs. 245-278, afirma igualmente que "es acorde con nuestro marco constitucional que la Administración Pública satisfaga sus necesidades (en el cumplimiento de los fines que le han sido atribuidos) a través de sus propios medios productivos. (...) la razón de instrumentalización, derivada de la decisión de autoorganización de la matriz, supera por entero a la idea de personificación, abriendo camino a una interpretación de lo que haya de entenderse por "medio propio" que sea comprensiva tanto de los órganos o servicios sin personalidad como de las entidades instrumentales con personalidad jurídica propia”.

19 Abunda esta calificación en la normativa autonómica. Como ejemplos podemos citar en el ámbito de la Comunidad Autónoma de Andalucía: Decreto 384/1996, de 2 de agosto que modifica el D 86/1992, de 19 de mayo relativo a la sociedad Gestión de Infraestructuras de Andalucía, SA (GIASA) cuyo art. 7 dispone: "1.La atribución a la Sociedad de la gestión de actuaciones se realizará por la Consejería de Obras Públicas y Transportes mediante resolución del Consejero en la que se determine las actuaciones a desarrollar y los compromisos para ambas partes. 2. Las relaciones que la Sociedad establezca con otras Administraciones, Organismos, Entidades o Empresas Públicas en relación con las actuaciones atribuidas por la Consejería de Obras Públicas y Transportes, deberán formalizarse mediante contrato o convenio en el que se determine todos los compromisos para cada parte y especialmente los relativos a garantías de cumplimiento de las obligaciones de pago. 3. A los efectos del art. 153 de la Ley de Contratos de las Administraciones Públicas, la Sociedad tendrá la consideración de medio propio de la Administración”.

Decreto 117/1998, de 9 de junio, que modifica el Decreto $17 / 1989$, de 7 de febrero, de constitución de la Empresa de Gestión Medioambiental, SA. El artículo 7 queda redactado en los siguientes términos: "1.EGMASA, como medio propio instrumental y servicio técnico de la Administración, está obligada a realizar los trabajos que, en las materias que constituyen el objeto social de la empresa y, especialmente, aquellos que sean urgentes o que se ordenen como consecuencia de las situaciones de emergencia que se declaren, le encomienden: La Administración de la Comunidad Autónoma de Andalucía, los organismos públicos dependientes de ella, así como las Corporaciones Locales en el ámbito de la Comunidad Autónoma de Andalucía que suscriban a tal fin un convenio de colaboración con la Junta de Andalucía. 2. Las Administraciones Públicas de las que EGMASA resulte ser medio propio instrumental podrán realizar abonos a cuenta de la empresa, en concepto de anticipo de los trabajos cuya realización le encomiende. 3. En las 
La relación de instrumentalidad tiene como esencial la dependencia de la entidad matriz, por lo que sería una contradicción admitir que pueda existir una relación jurídica en la que matriz e instrumental ocupen posiciones de igual rango, premisa que define el negocio convencional o contractual. Por consiguiente, entre la matriz y la instrumental sólo caben relaciones de subordinación, a través de la potestad de dirección, como forma de articular el cumplimiento de fines de la matriz a través de la instrumental ${ }^{20}$. A lo que habría que añadir, como ha destacado el profesor REBOLLO PUIG, que la parte esencial de su actividad consista en la que se deriva de ser "medio propio de

actuaciones en que EGMASA actúe como medio propio de la Administración, al tiempo de que se le encomienden los trabajos por las distintas Administraciones Públicas, se designará al personal de dicha Administración o de EGMASA que deba actuar como Director Facultativo, quien certificará la aplicación de las tarifas aprobadas por la Administración a las unidades efectivamente producidas, sirviendo dicha certificación, a los efectos de fiscalización, como justificante de la inversión o de los servicios realizados. 4. En las actuaciones en que EGMASA actúe como medio propio de la Administración, y en cumplimiento de lo dispuesto en los artículos 153 y 195 de la Ley 13/1995, de 18 de mayo, de Contratos de las Administraciones Públicas, si la ejecución de obras o la fabricación de bienes muebles por EGMASA se verifica con la colaboración de empresarios particulares, el importe de ésta será inferior a 799.882 .917 pesetas con exclusión del Impuesto sobre el Valor Añadido, o inferior al importe señalado en el artículo 178.2 de la referida Ley, cuando se trate de la fabricación de bienes muebles. Lo establecido en la Disposición Adicional Primera de la Ley 13/1995, de 18 de mayo, de Contratos de las Administraciones Públicas, será de aplicación a lo dispuesto en el presente apartado. 5. Ni EGMASA ni sus filiales o participadas mayoritariamente podrán participar en los procedimientos para la adjudicación de contratos convocados por las Administraciones Públicas de las que sea medio propio. No obstante, cuando no concurra ningún licitador podrá encargarse a EGMASA la ejecución de la actividad objeto de licitación pública. 6. El importe de las obras, trabajos, proyectos, estudios y suministros realizados por medio de EGMASA se determinará aplicando a las unidades ejecutadas las tarifas correspondientes, que deberán ser objeto de aprobación por la Administración competente. Dichas tarifas se calcularán de manera que representen los costes reales de realización y su aplicación a las unidades producidas servirá de justificante de la inversión o de los servicios realizados. 7. Sin perjuicio de lo establecido en los apartados anteriores, EGMASA podrá realizar actuaciones, trabajos, obras, asistencias técnicas, consultorías, prestación de servicios y comercialización de sus productos dentro o fuera del territorio nacional, directamente o a través de sus filiales o participadas".

${ }^{20}$ Vid. Ortiz Mallol, J "La relación de dependencia de las entidades instrumentales de la Administración pública: algunas notas", ob. cit. que analiza los rasgos definidores de la relación de instrumentalidad con los que estamos de acuerdo: el fin o servicio no es propio del ente instrumental, sino de la Administración matriz, quien mantiene su titularidad y sobre la que recae la responsabilidad política de su organización y de su rendimiento; la conformación de un complejo organizativo unitario entre la Administración matriz y el ente instrumental quedando éste adscrito a aquélla; la relación jurídica naciente no es asimilable a la jerarquía; la dependencia y comunicabilidad se extienden a la esfera económico financiera; la dependencia tiene su particular consecuencia en las relaciones entre el patrimonio de la Administración matriz y de la entidad instrumental. Asimismo, véase el estudio de Rebollo Puig, M. "Los entes institucionales de la Junta de Andalucía y su utilización como medio propio", $R A P, \mathrm{n}^{\circ} 161$, 2003, en particular págs. 376 y ss. 
su Administración matriz", o en términos de la STJUE de 18 de noviembre de 1999, caso Teckal, que el ente instrumental realice la parte esencial de su actividad con el ente o los entes que la controlan ${ }^{21}$.

La cuestión es determinar las consecuencias que tiene la utilización de los medios propios para los terceros potencialmente interesados en la concurrencia a tal objeto prestacional, y si así se vulnera algún derecho o interés amparado por el ordenamiento jurídico. Desde la perspectiva de nuestro ordenamiento interno, los posibles bienes jurídicos afectados por tal proceder son: derecho a ser contratista de la Administración, contenido esencial de la libertad de empresa, y la libre competencia.

Pero, de una parte, ni hay un derecho constitucional a ser contratista de la Administración, no le es aplicable el art. 23.2 CE, y de otra, por lo que se refiere a la libertad de empresa de la jurisprudencia del TC se infiere que su contenido esencial no comprende un deber de los poderes públicos de garantizar un determinado mercado a los empresarios privados en todos los sectores, y menos aún el deber de garantizar un determinado nivel de contratación con las Administraciones públicas. Como ha manifestado HUERGO LORA ${ }^{22}$ una interpretación de la libertad de empresa garantizada en el art. 38 CE en el sentido de implicar una reserva incondicionada al sector privado de cuantas oportunidades de contratación o negocio surjan en la actuación administrativa, de tal modo que sería inconstitucional toda norma que reserve alguna de esas oportunidades para la gestión directa por parte de la Administración, por sí o a través de una sociedad en mano pública, carece de fundamento, pues supondría extraer del Texto Constitucional la regla del contratista interpuesto ${ }^{23}$.

21 Pues el peligro está en que el ente instrumental haga simultáneamente las tareas como medio propio y concurra a la vez en el mercado para ofrecer bienes y servicios a los particulares en competencia con las empresas privadas. Pues si al mismo tiempo que actúan y obtienen financiación como medio propio de la Administración, concurren en el mercado, es difícil evitar que la entidad instrumental no parta con ventaja sobre las empresas privadas, y que se rompa la real igualdad con las que compite. En cualquier caso, casi inevitablemente habrá una competencia con cierta ventaja de quien tiene la subsistencia asegurada gracias a su trabajo para la Administración, lo que le permite costear sus gastos de personal y amortizar fuertes inversiones, en "Los entes institucionales de la Junta de Andalucía y su utilización como medio propio”, ob. cit., pág. 388.

22 Consúltese el trabajo de Huergo Lora, A. "Libertad de empresa y la colaboración preferente de las Administraciones con empresas públicas" RAP n⿳ำ 154, 2001, págs. 129-171, en particular págs. 151-157 y 168-171.

${ }^{23}$ En este mismo sentido se manifiesta acertadamente Rebollo Puig, M. "Los entes institucionales de la Junta de Andalucía y su utilización como medio propio”, ob. cit. y subraya el profesor 
Supondría asimismo una restricción a la potestad de iniciativa pública económica y a la potestad autoorganizatoria de la Administración carente de fundamento en nuestro orden económico constitucional que por ejemplo reconoce la potestad de reserva de recursos y servicios esenciales, lo cual se configura como una potestad "más" que la potestad "menos" de actuar sus competencias, funciones y actividades de su titularidad a través de sus propios entes personificados, sean éstos de Derecho público o de Derecho privado.

Por ello, manifiesta certeramente ORTIZ MALLOL "la Administración puede decidir si actúa con medios propios (orgánicos o personificados) o requiere de la colaboración de un tercero para la realización de sus competencias y la consecución del interés general. Precisamente, el hecho de que la Administración persiga un interés general que se sobrepone frente al interés particular del interesado en contratar con ella es el que determina la negación de un derecho subjetivo a "ser contratista". Lo que sí existe es un derecho subjetivo a que, cuando la Administración decide acudir a la contratación, se produzca la misma con concurrencia, publicidad y que, luego del procedimiento que se realice, se decida en adjudicación motivada y objetivamente" ${ }^{24}$.

El TRLCAP da sólidos argumentos para esta solución lógica. De una parte, porque en virtud del art. 154.2 sólo se excluye del contrato de gestión de servicios públicos la creación de Entidades de Derecho público o de una sociedad mercantil de capital exclusivo de la Administración o de un ente público de la misma. Y de otra parte, en el seno de la regulación del contrato de concesión de obra pública pues el art. 237 dispone que:

“2. El concesionario deberá someter los contratos que celebre con un tercero a las normas de publicidad establecidas en el art. 135.2, salvo cuando mediare cualquiera de las circunstancias siguientes: (...)

\footnotetext{
Rebollo Puig que en estos supuestos no tiene que haber ningún contrato o convenio, ni tiene sentido que lo haya, pues todo se produce en virtud de la decisión unilateral de la Administración matriz, que es determinante de la relación que surge. La decisión de realizar la obra, el suministro, el estudio o el proyecto por medio del ente institucional es exclusiva de la Administración matriz. Por ende no es necesario el consentimiento del ente institucional, que, como mero instrumento que es, está obligado a realizar lo que se le ordene, exactamente igual que lo está un servicio no personificado. Hay sólo un acto administrativo con una serie de efectos que no son contractuales (págs. 383-384).

${ }^{24}$ Ortiz Mallol, J. "La relación de dependencia de las entidades instrumentales ...", ob. cit. págs. 270-271.
} 
A efectos de lo establecido en el apartado anterior, no se considerarán terceros aquellas empresas que se hayan agrupado para obtener la concesión, ni las empresas vinculadas a ellas (...)”.

De nuevo en Derecho Administrativo surge la noción de vinculación que define el art. 234.1 y 2 TRLCAP asíîisis:

"1. Se entiende por empresas vinculadas aquellas en las que el concesionario pueda ejercer, directa o indirectamente, una influencia dominante o aquellas que puedan ejercerla sobre él o que, del mismo modo que el concesionario, estén sometidas a la influencia dominante de otra empresa por razón de propiedad, participación financiera o normas que la regulen. 2. Se presumirá que existe influencia dominante cuando una empresa, directa o indirectamente, con relación a otra:

a) Esté en posesión de la mayoría del capital suscrito.

b) Disponga de la mayoría de los votos inherentes a las participaciones emitidas por la empresa.

c) Pueda designar más de la mitad de los miembros del órgano de administración, dirección o control de la empresa”.

De tal manera que si en estos supuestos el concesionario queda liberado del mandato de publicidad con más razón cuando se trate de la propia Administración.

Distinto es el caso de las relaciones con las sociedades mixtas, es decir, aquellas en las que junto a la Administración participan sujetos privados que persiguen sus propios intereses que no tienen que ser coincidentes con el interés general. Aquí las relaciones entre la Administración y la sociedad mercantil se sujetan a los procedimientos de licitación que regula el TRLCAP. Con la redacción del art. 154.2 TRLCAP no es posible adjudicarles directamente un contrato de gestión de servicios públicos ${ }^{25}$.

24bis Por vez primera se emplea en Derecho Administrativo la noción de entidades vinculadas o dependientes en la LPAC para definir en su art. 2.2 su ámbito subjetivo de aplicación. Véase acerca de su interpretación Montoya Martín, E. Las empresas públicas sometidas al Derecho privado, Marcial Pons, Madrid, 1996, págs. 480 y ss.

${ }^{25}$ En el mismo sentido, Sosa Wagner, F. La gestión de los servicios públicos locales, ob. cit. págs.174176. Rebollo Puig. M. "Los entes institucionales de la Junta de Andalucía y su utilización como medio propio”, ob. cit. págs. 385-386. 
2. Desde la vertiente del Derecho comunitario: la STJUE de 13 de enero de 2005 .

Desde el plano del Derecho comunitario de la contratación pública procede dilucidar si se acomoda al ámbito de aplicación de las Directivas la figura de las encomiendas o encargos directos de los poderes adjudicadores a sus empresas públicas. Cuestión que a su vez remite al status de instrumentalidad o dependencia de la empresa pública mercantil respecto de la Administración matriz en aras de determinar si en estos supuestos existe o no verdadero contrato entre dos partes según la normativa comunitaria.

Destaca sobre este asunto la reciente Sentencia TJUE de 13 de enero de 2005 Comisión contra el R. De España (asunto C-84/03) que tiene por objeto un recurso por incumplimiento de las obligaciones que le incumben en virtud de las Directivas 93/36/CEE y 93/37/ CEE relativas respectivamente a los procedimientos de adjudicación de los contratos públicos de suministro y obras, al excluir del ámbito de aplicación del TRLCAP en el art. 1.3 a las entidades de Derecho privado; y de otro, que es lo que ahora nos importa, al excluir de forma absoluta del ámbito de aplicación material del TRLCAP en el art. 3.1.c los convenios de colaboración que celebren las Administraciones públicas con las demás entidades públicas y, por tanto, también los convenios que constituyan contratos públicos a efectos de las Directivas. A juicio de la Comisión se trata de una exclusión absoluta puesto que algunos de estos convenios pueden tener la misma naturaleza que los contratos públicos comprendidos en el ámbito de aplicación de las referidas Directivas, además de tratarse de una exclusión que no figura en las mismas.

Para el TJUE basta en principio que el contrato haya sido celebrado entre, por una parte, un ente territorial $y$, por otra, una persona jurídicamente distinta de éste. Sólo puede ser de otra manera en el supuesto de que, a la vez, el ente territorial ejerza sobre la persona de que se trate un control análogo al que ejerce sobre sus propios servicios y esta persona realice la parte esencial de su actividad con el ente o los entes que la controlan. Así con invocación de la doctrina anteriormente asentada en la sentencia de 18 de noviembre, de 1999 (asunto C- 107/98) caso Teckal ${ }^{26}$ concluye en el Cod 40 que al excluir "a

\footnotetext{
${ }^{26}$ La sentencia trae causa en la cuestión prejudicial planteada al Tribunal de Justicia por el Tribunal administrativo regional para L'Emilia-Romagna en el litigio pendiente entre Teckal Srl y el municipio de Viano y la Azienda Gas- Acqua Consorziale (AGAC) de Regio Emilia acerca de la adjudicación, por parte de este municipio, de la gestión del servicio de calefacción de determinados edificios municipales. Los hechos que dieron lugar al litigio se centran en el acuerdo del Ayuntamiento de Viano en virtud del cual confió a la AGAC la gestión del servicio de calefacción de determinados edificios municipales, acuerdo que no estuvo precedido de ningún procedimiento de
} 
priori del ámbito de aplicación del Texto Refundido las relaciones entre las Administraciones Públicas, sus organismos públicos y, en general, las entidades de Derecho público no mercantiles, sea cual sea la naturaleza de estas relaciones, la normativa española de que se trata en el caso de autos constituye una adaptación incorrecta del Derecho interno a las Directivas 93/36 y 93/37". Por ende, el fallo declara el incumplimiento de España de las obligaciones que le incumben en virtud de las Directivas 93/36/CEE y 93/37/CEE al excluir del ámbito de aplicación del TRLCAP en el art. 1.3 a las entidades de Derecho privado que reúnan los requisitos recogidos en el art. 1.b de cada una de las mencionadas Directivas; al excluir de forma absoluta del ámbito de aplicación del Texto Refundido y en concreto del art. 3.1.c) de éste los convenios de colaboración que celebren las Administraciones públicas y, por tanto, también los convenios que constituyan contratos públicos a efectos de dichas Directivas.

C) La modificación TRLCAP por el Real Decreto Ley 5/2005, de 11 de marzo, de reformas urgentes para el impulso a la productividad y para la mejora de la contratación pública.

Esta modificación ha supuesto de una parte, la incorporación al ámbito subjetivo del TRLCAP de las fundaciones del sector público cuando reúnan

licitación. La misión de AGAC consiste específicamente en la explotación y mantenimiento de las instalaciones de calefacción de diversos edificios municipales, incluidas las intervenciones de mejora necesarias, así como el suministro de combustible. Por su parte Teckal es una empresa privada que desempeña sus actividades en el ámbito de los servicios de calefacción, suministrando a particulares y a organismos públicos el gasóleo que compra previamente a las empresas productoras. Además de ocuparse del mantenimiento de instalaciones de calefacción que funcionan con gasóleo y con gas. En definitiva, el municipio de Viano confió mediante un acto único, tanto la prestación de determinados servicios como el suministro de determinados productos. Al ser superior el valor de los productos se rige por la Directiva 93/36 relativa a los contratos públicos de suministro. Según el TJ el municipio como ente territorial es una entidad adjudicadora y por consiguiente corresponde al juez nacional verificar si la relación entre dicho municipio y AGAC reúne también los demás requisitos exigidos por la Directiva 93/36 para constituir un contrato público de suministros. Así será siempre que se trate de un contrato celebrado por escrito a título oneroso que tiene por objeto, en le caso de la Directiva 93/36, en particular, la compra de productos. Consta que la AGAC suministra combustible al municipio de Viano mediante pago de un precio. Y por lo que se refiere a la existencia de contrato, es decir, un convenio entre dos personas distintas manifiesta el TJ que: "basta, en principio con que el contrato haya sido celebrado entre, por una parte, un ente territorial y, por otra, una persona jurídicamente distinta de éste. Sólo puede ser de otra manera en el supuesto de que, a la vez, el ente territorial ejerza sobre la persona de que se trate un control análogo al que ejerce sobre sus propios servicios y esta persona realice la parte esencial de su actividad con el ente o los entes que la controlan (Cdo 51).

Por consiguiente, procede responder a la cuestión prejudicial que la Directiva 93/36 es aplicable cuando una entidad adjudicadora, como un ente territorial, proyecta celebrar por escrito, con una entidad formalmente distinta de ella y autónoma respecto a ella desde el punto de vista decisorio, un contrato a título oneroso que tiene por objeto el suministro de productos, independientemente de que dicha entidad sea o no, en sí misma, una entidad adjudicadora (Cdo 51)". 
los requisitos definidores del concepto de Organismo de derecho público, y de otra parte, la adecuación del TRLCAP a la citada sentencia de 13 de enero de 2005 por lo que el art. 3.1.c) queda redactado en los términos siguientes:

"Los convenios de colaboración que celebre la Administración General del Estado con la Seguridad Social, las Comunidades Autónomas, las entidades locales, sus respectivos organismos autónomos y las restantes entidades públicas o cualquiera de ellos entre sí, siempre que la materia sobre la que verse no sea objeto de un contrato de obras, de suministro, de consultoría y asistencia o servicios, o que siendo objeto de tales contratos su importe sea inferior, respectivamente, a las cuantías que se especifican en los arts. 135.1, 177.2 y 203.2”.

Asimismo, se añade un nuevo apartado, letra 1 a este mismo art. 3.1 que excluye del ámbito material de aplicación de la Ley:

"Las encomiendas de gestión que se realicen a las entidades y a las sociedades cuyo capital pertenezca totalmente a la propia Administración pública”.

Por ende, sólo quedan al margen del TRLCAP los encargos, encomiendas o contratos-programas que celebre una Administración territorial matriz con sus propias entidades o sociedades instrumentales. Quiere decirse que al entablarse dicha relación de dependencia únicamente con la matriz bien de manera directa o indirecta -ahora el art. 85.2.A.d) LBRL califica de sociedad mercantil local la participada en exclusiva de manera directa por la Administración local o a través de una entidad pública dependiente de la misa-, no puede, por definición, erigirse en medio propio de otra Administración pública, pues en tal supuesto, siempre que la materia sobre la que verse sea objeto de un contrato de obras, de suministro, de consultoría y asistencia o servicios, cualquiera que sea la denominación del vehículo a través del cual se quiera canalizar dicha relación, -encargo, encomienda, contrato-programa o convenio-, existe un verdadero contrato al que es de aplicación preceptiva el TRLCAP. Además, no cabe su elusión por la vía de proclamar en el grupo normativo ad hoc aplicable al ente instrumental que es medio propio de otra u otras Administración si realmente no lo es ${ }^{27}$. Este es el requisito que subraya

${ }^{27}$ En este sentido se manifiesta también Rebollo Puig, M. "Los entes institucionales de la Junta de Andalucía y su utilización como medio propio”, ob. cit. pág. 386-387. Así puede ponerse como ejemplo llamativo el caso de la sociedad estatal Empresa de Transformación Agraria, SA (TRAGSA), cuya constitución fue autorizada por Decreto 379/1977, de 22 de enero, sustituido por el vigente Decreto 371/1999, de 5 de marzo, dictado en desarrollo de la Ley 66/1997, de 30 
el nuevo apartado 1 del art. 3.1 TRLCAP, criterio que ya viene siendo sustentado por la jurisprudencia de los Tribunales Superiores de Justicia ${ }^{28}$, por cierto, en los tres casos, con relación a sociedades de gestión del ciclo integral del agua.

de diciembre, de Medidas fiscales, administrativas y del orden social, cuyo art. 88 regula el régimen jurídico de TRAGSA con pleno respeto a la autonomía de las CCAA y confirma la naturaleza instrumental de TRAGSA para que, por sí misma o sus filiales, realice sus actuaciones en su condición de medio propio instrumental y servicio técnico de la Administración General del Estado y de las Administraciones de las CCAA que así lo dispongan, perfeccionando las relaciones con éstas al establecer la posibilidad del acceso de las propias CCAA a su capital social. Interesa destacar el régimen jurídico preceptuado en el art. 3: "1.TRAGSA y sus filiales son medio instrumental y servicio técnico de la Administración General del Estado y de cada Comunidad Autónoma interesada. 2. Los diferentes Departamentos o Consejerías de las citadas Administraciones Públicas, así como sus organismos dependientes y las entidades de cualquier naturaleza vinculadas a aquéllas para la realización de sus planes de actuación, podrán encomendar a TRAGSA o a sus filiales los trabajos y actividades que precisen para el ejercicio de sus competencias y funciones, así como las que resulten complementarias o accesorias, de acuerdo con el régimen establecido en este Real Decreto. 3. TRAGSA y sus filiales están obligadas a realizar los trabajos y actividades que le sean encomendados por la Administración. Dicha obligación se refiere, con carácter exclusivo, a los encargos que les formule como su medio propio instrumental y servicio técnico, en las materias que constituyen su objeto social.... 7. Las relaciones de TRAGSA y sus filiales con las Administraciones públicas en su condición de medio propio y servicio técnico tienen naturaleza instrumental y no contractual, por lo que, a todos los efectos, son de carácter interno, dependiente y subordinado". Las encomiendas o encargos son válidos cuando los realiza la Administración del Estado a TRAGSA a la vista de la configuración de su capital social, pero no son conformes a Derecho, y desde luego a la jurisprudencia comunitaria cuando el poder adjudicador sean las CCAA o Entidades locales, porque en este caso no hay relación de dependencia ni tampoco un control o dominio efectivo del poder adjudicador sobre TRAGSA, por más que el art. 88 de la Ley 66/1997 así lo configure y le imponga la obligación legal de cumplir las encomiendas ordenadas por las CCAA. Vid. ampliamente sobre el caso de TRAGSA Amoedo Souto, C. TRAGSA. Medios propios de la Administración y huida del Derecho administrativo, Atelier, Barcelona, 2004.

${ }^{28} \mathrm{El}$ profesor Sosa Wagner ha manifestado su convicción "acerca de la posibilidad natural que el Ordenamiento brinda a las entidades públicas de emplear sus "recursos propios", sin necesidad de recurrir a contratos externos, cuando cuenta con los medios suficientes para ello. Las figuras de la encomienda o el encargo hechos a organizaciones en todo dependientes nos sirven para explicar estas singulares relaciones, como igualmente nos sirven los convenios para entender el uso que una Administración pública pueda hacer de organizaciones instrumentales pertenecientes a otras Administraciones. Sin embargo no compartimos esta última afirmación de entender como simples convenios, fuera del TRLCAP los relativos a la utilización de entes instrumentales de una Administración pública por otra. No obstante su postura favorable en general, el profesor Sosa alude también a los límites en la utilización de los recursos propios representados por el principio de proporcionalidad, adecuación entre la envergadura de las organizaciones instrumentales y la capacidad de prestación del Ayuntamiento y sus previsibles necesidades; la capacidad y envergadura de los "medios propios" de que dispone la Administración; y el control y erradicación de prácticas restrictivas de la competencia que no encuentren amparo legal en los términos del art. 2.1 de la Ley de Defensa de la Competencia. Vid. Sosa Wagner, F. "El empleo de los "recursos propios" por las Administraciones locales”, Estudios de Derecho Público Económico, Libro Homenaje al Prof. 
Pionera en este sentido es la STSJ de Castilla-La Mancha de 30 de octubre de 2000 (Arz. 2309) que anula el Convenio interadministrativo de colaboración entre el Ayuntamiento de Huete y el Ayuntamiento de Alcázar de San Juan a través de la empresa de capital íntegramente municipal que presta el servicio de suministro o abastecimiento de agua en dicho municipio, por medio del cual se formaliza una encomienda de gestión del servicio público del agua. La parte recurrente sostiene que se trataba de un fraude de ley para encubrir una auténtica desmunicipalización del servicio al confiarse a una entidad mercantil de las consideradas municipales, al margen de las formalidades legalmente impuestas a la contratación administrativa y a la concesión de servicios públicos. El TSJ manifiesta que:

"el convenio encubre una auténtica concesión o cesión de la gestión del servicio público por un tercero distinto de la propia Administración local titular del servicio que hasta ese momento venía prestándolo de forma directa, siendo ese tercero en este caso la empresa municipal de otra entidad local constituida para la gestión directa del servicio de abastecimiento de agua potable en su municipio. Se utiliza la figura del convenio intermunicipal, pero esta institución no es sino una cobertura meramente nominal o formal de lo que realmente ocurre: la transferencia de potestades administrativas para la gestión de un servicio público municipal a una persona jurídica privada que actúa en el tráfico jurídico como una sociedad mercantil aunque se haya constituido por una entidad local diferente para la gestión en el ámbito del propio municipio de ese mismo servicio. En consecuencia, dicha cobertura ha de considerarse fraudulenta. En realidad, se pasa a un sistema de gestión indirecta del servicio público de que se trata".

Analizando el art. 15 Ley 30/92 la encomienda de gestión afirma el Tribunal en el F.J. Quinto que en este supuesto no sólo se encomiendan actividades materiales, técnicas o de servicios de la competencia municipal sino que

\footnotetext{
Dr. D. Sebastián Martín-Retortillo, ob. cit. págs. 1339-1340. Asimismo, sostiene en la $6^{\mathrm{a}}$ edic de su obra La gestión de los servicios públicos locales, Thomson, Civitas, 2004, pág. 54, la licitud de un convenio entre Administraciones públicas de colaboración al amparo de lo previsto en el art. 57 LBRL y del principio de libertad de pactos que anima la contratación administrativa, convenio que puede servir de cobertura a la transferencia de la gestión de un servicio público a una empresa cuyas acciones se hallen en manos de la Administración con la que se conviene. Mas entiendo que dicho criterio no puede compartirse, de una parte en virtud de la noción de medio propio o instrumental de la Administración, que implica en todo caso una relación de subordinación entre ésta y el ente instrumental, y, de otra parte, como consecuencia de la STJU de 13 de enero de 2005 y de la letra 1 del art. 3.1 TRLCAP introducida por el Real Decreto Ley 5/2005.
} 
se ceden ciertas competencias administrativas sin que la empresa cesionaria precise en esos supuestos del soporte de actos o resoluciones concretos (...).

Más recientemente, se ha pronunciado en dos ocasiones sobre parecido asunto el TSJ de Valencia, en las sentencias de 13 de marzo de 2003 (Arz. 22703) y 19 de mayo de 2004 (Arz. 79) ${ }^{29}$-que reproduce literalmente los términos de la precedente-, con ocasión de la constitución de la empresa mixta Aigües de L’Horta entre el Ayuntamiento de Torrente e Hidra Gestión Integral del Agua, SA, sociedad de capital mayoritario municipal para la gestión del ciclo integral del agua en Torrente. Posteriormente, el Ayuntamiento de Picanya solicitó al de Torrente que a través de un convenio interadministrativo se regule la cooperación para la prestación del agua por dicha empresa mixta. El 24 de julio de 1997 la empresa mixta modificó sus estatutos a fin de que no tenga por objeto social exclusivo la prestación en un determinado término municipal estableciendo que también podrá prestar sus servicios en otros municipios que hayan concertado con el Ayuntamiento de Torrente las prestaciones en régimen de cooperación municipal.

Ambos fallos se pronuncian estando vigente LCAP, cuyo art. 155.2 criterio posteriormente modificado por TRLCAP (art. 154.2) excluía del contrato de gestión de servicios a la sociedad mercantil de participación mayoritaria de la Administración o de una entidad pública por considerarlo como un modo directo de gestión de los servicios públicos.

Asimismo, en ambos pleitos la recurrente es la sociedad Aguas de Valencia SA, entidad mercantil que tiene como objeto social básico el de desarrollar una actividad de prestación indirecta de los servicios públicos municipales de abastecimiento de agua potable, saneamiento, evacuación y depuración de aguas residuales, cuyo ámbito geográfico mayoritario de actuación es la Co-

\footnotetext{
${ }^{29}$ Sentencia en la que el TSJ ante supuestos sustancialmente iguales sostiene el mismo criterio que en la precedente. En esta ocasión Aguas de Valencia SA impugna los acuerdo del Ayuntamiento de Torrente de fechas 25 de enero y 7 de febrero de 2000, por los que respectivamente se aprueba el convenio interadministrativo a suscribir entre el Ayuntamiento de Torrente y el Ayuntamiento de Paterna por el que se regula la cooperación para la prestación del servicio de agua potable y alcantarillado en el municipio de Paterna, así como el convenio interadministrativo por el que se regula la gestión, por el Ayuntamiento de Torrente a través de su Sociedad mixta Aigües de L'Horta, SA, del servicio de captación, abastecimiento y distribución domiciliaria de agua potable a los abonaos al servicio en el término de Paterna, así como la gestión del alcantarillado, saneamiento y depuración de las aguas residuales de este último municipio, suscrito el 9 de febrero de 2000 entre los Ayuntamientos de Torrente y Paterna y la empresa Aigües de L'Horta, SA en cumplimiento de los referidos acuerdos municipales.
} 
munidad autónomo Valenciana donde tiene una sólida implantación. La SA demandante opone en síntesis, vulneración del principio de libre competencia, quedando la actuación fuera del marco de la Ley de Contratos, aplicando indebidamente lo dispuesto en el art. 155.2 de la misma e infringiendo con ello lo dispuesto en los arts. 96 y 97 TRRL, el art. 38 CE y la Ley 3/1991, de Competencia Desleal.

Para el TSJ de Valencia el punto de partida ha de ser la distinta valoración que corresponde a la utilización de una sociedad mercantil en la que el capital mayoritario pertenece a una Administración Local distinta a la prestataria del servicio público de agua potable y alcantarillado, pautas esenciales que condicionan la respuesta judicial a la controversia planteada. Del F.J Quinto de la sentencia de 13 de marzo de 2003 (relativa al acuerdo del Ayuntamiento de Silla por el que se aprobó el convenio interadministrativo entre los Ayuntamientos de Silla y Torrente) importa destacar:

“a) (...) Así, como punto de partida, parece evidente que no pueden catalogarse como actos administrativos equiparables y, en principio, sujetos a las mismas condiciones aquél que consiste en la propia prestación del servicio por parte de la Administración titular del mismo -y en el que existe únicamente una modulación (por importante que ésta sea, pero modulación al fin y al cabo) en la forma jurídica de desarrollar la gestión: entidad de Derecho privado- con aquél que consiste en la prestación del servicio por un tercero por más que en el ámbito interno de este tercero aparezca una persona pública dominando la vida social del ente privado.

b) (...) la gestión del servicio público de abastecimiento de agua potable y alcantarillado en el municipio de Xirivella no va a ser prestado por una persona jurídica en la que esta Administración Local disponga la mayoría en el número de sus participaciones sociales sino por una tercera persona jurídica que cuenta con ese nivel participativo pero a favor de un Ayuntamiento vecino (Torrente).

c) No hay aquí, entonces, una gestión directa del servicio público por parte de la Administración Local titular del mismo sino una gestión indirecta de éste por un tercero. (...).

d) Para lo que interesa en esta litis, Aigües de L'Horta SA es igual de tercero que cualquier otra persona jurídica de Derecho privado al no mediar vinculación alguna entre esta persona y el Ayuntamiento de Xirivella. Y es que la participación mayoritaria en esta sociedad del Ayuntamiento de Torrente 
cuenta con relevancia dentro del propio espacio físico en el que este municipio desarrolla una actividad prestacional de servicios pero no cuando los mismos se ejercen extramuros de tal localidad. En este supuesto, la sociedad por él constituida pierde los rasgos singulares que le son característicos para entrar en el merado como una entidad más que trata de diseñar su volumen negocial por el cauce de un incremento en la prestación de servicios públicos -objetivo tendencial explícito de la sociedad-que le pueden ser adjudicados.

f) El art. 155.2 LCAP establece una previsión normativa que, por su propia naturaleza -al introducir una restricción para la aplicabilidad de los principios de competencia y publicidad-debe interpretarse de forma estricta (...).

Es verdad que la norma utiliza, in genere, el vocablo "la Administración" al afirmar que "... en cuyo capital sea exclusiva o mayoritaria la participación de la Administración", pero, como aclara el criterio sistemático, resulta que sólo cuando sea la propia Administración beneficiaria del servicio la que domine la nueva persona jurídica constituida al efecto podrá afirmarse que la gestión del servicio público corresponde a la propia Administración titular del mismo que es aquella enunciada en el art. 155.2 LCAP.

g) ... lo esencial aquí es, la existencia de una persona jurídica de Derecho privado que se introduce en el mercado como cualquier otro tercero al objeto de desarrollar una actividad mercantil que, en principio, está sometida a la libre concurrencia y publicidad salvo cuando, y de modo excepcional, la prestación del servicio se desarrolle por un ente instrumental de Derecho privado de la propia Administración pública titular del servicio".

En ambas sentencias resulta interesante cómo se rebaten los argumentos jurídicos sostenidos por la parte demandada. En efecto, en el escrito de contestación a la demanda que presenta Aigües de L'Horta SA se mantiene que una vez establecida una actividad económica que reviste el carácter de servicio público, el Ayuntamiento puede extenderla a otros municipios si lo considera oportuno, pues la cooperación administrativa forma parte de la potestad autoorganizatoria de los municipios... Al suscribir el convenio impugnado, el Ayuntamiento no está ampliando el ejercicio de una actividad económica, sino prestando su servicio a otro municipio en régimen de cooperación. Mas el TSJ en la letra h del F.J. Quinto de la sentencia de 13 de marzo de 2003 afirma que:

"Para nosotros, una cosa es la potestad autoorganizatoria de las Administraciones públicas -caracterizadas por su extrema discrecionalidad y que, in- 
dudablemente, posibilita la suscripción de un convenio interadministrativo como aquél que constituye el objeto inicial sobre el que se articulan las pretensiones de invalidez que Aguas de Valencia SA formula en el proceso- y otra es el respeto de las exigencias ordinamentales de libre concurrencia y publicidad que fija la normativa de contratación de Derecho público.... Desde el primer parámetro, los Ayuntamientos de Xirivella y Torrent pueden convenir un cierto ámbito regulativo como es la ayuda para al prestación de un servicio pero esta potestad autoorganizatoria ha de cohonestarse con el resto del ordenamiento jurídico al objeto de constatar si, efectivamente, la misma no vulnera normas imperativas.

Para lo que ahora nos interesa, resulta que en el ejercicio de esa autoorganización ambos Ayuntamientos pretenden excluir la aplicabilidad de una normativa forzosa -y de carácter básico- para la contratación pública y que configura uno de los pilares sobre los que asienta la LCAP de mayo de 1995 $(\ldots)$

Sobre el basamento de lo expuesto, obtenemos la conclusión de que si bien el Convenio interadministrativo suscrito el 27 de marzo de 2000 no queda sometido, en sí mismo, a las normas de contratación pública que recoge la Ley de 18 de mayo de 1995 (... art. 3.1.c de la Ley 13/1995 ...), sucede que ésta, al infringir el Derecho aplicable, contiene un régimen regulativo del servicio público de abastecimiento de agua potable y alcantarillado en el municipio de Xirivella que supone una exclusión ilícita de la normativa legal aplicable en materia de contratación pública: libre concurrencia a la prestación del servicio si no se opta por la prestación directa del mismo a través del propio Ente público sea por sí mismo o por medio de la constitución de una persona pública o privada interpuesta".

Por consiguiente, el fallo estima el recurso interpuesto por Aguas de Valencia, SA contra acuerdo del Pleno del Ayuntamiento de Silla por el que se aprobó el Convenio interadministrativo entre los Ayuntamientos de Silla y Torrente al objeto de regular la cooperación para la prestación del servicio de agua potable y alcantarillado en el municipio de Silla y el convenio suscrito en cumplimiento de dicho acuerdo, que se anulan y se dejan si efecto.

\section{CONCLUSIONES}

La reforma de los servicios locales y sus formas de gestión tiene como presupuesto previo una definición positiva y actualizada de las competencias lo- 
cales y un aggiomamento de la noción de servicio público como categoría, finalidades que exceden del propósito más modesto de la reforma operada por la Ley 57/2003 de Medidas para la Modernización del Gobierno local (LMMGL). Además urge actualizar la lista de las competencias y servicios locales a los tiempos que vivimos y despojarlos del sabor decimonónico que tienen algunos de los servicios que se enumeran por ejemplo en art. 86.3 LBRL. Por el contrario, es preciso añadir otros, que de hecho, aunque sin cobertura financiera, vienen prestando los municipios, como por ejemplo servicios de atención a los inmigrantes.

La Exposición de Motivos de la LMMGL anuncia la elaboración de una nueva LBRL, "en un tiempo razonable pero no dilatado", y afirma que se incorporan en la Ley las reformas inaplazables tendentes a su racionalización y modernización, que responden a necesidades ineludibles. Mas en puridad respecto de los servicios públicos locales y sus formas de gestión lo aportado es menos de lo que se anuncia. Pues la Exposición de Motivos de la LMMGL señala como novedades: una nueva clasificación de las diversas formas de gestión de los servicios públicos, que no es tal, toda vez que la clasificación no varía, sino que se limita a introducir como modo de gestión directa la fórmula de las EPES locales; la incorporación a la ley de una regulación sustancial necesaria de los Organismos autónomos y de las sociedades mercantiles con capital público, hasta ahora sólo reguladas parcialmente en normas reglamentarias. En particular, por lo que respecta a la sociedad mercantil local como modo de gestión directa destaca la prohibición expresa de desempeñar funciones de autoridad, a tenor del nuevo art. 85.3 LBRL. Este precepto conlleva la necesidad de aclarar la situación de determinadas sociedades de capital exclusivo local que realizan por ejemplo la gestión del sistema tributario; o actos de inspección en el caso de sociedades municipales de abastecimiento de aguas; resolución de expedientes de desahucio administrativo en caso de sociedades promotoras de viviendas sociales; o, actividad subvencional llevada a cabo por las numerosas sociedades de desarrollo local existentes.

La reforma de la Ley 57/2003, de 16 de diciembre ha tenido como finalidad uniformar las modalidades organizativas instrumentales a imagen y semejanza de la LOFAGE, pero desde perspectivas distintas: mientras que la LOFAGE se sitúa en el Título III desde la vertiente de las modalidades de organización de la Administración institucional del Estado, en definitiva, la teoría de la organización, en cambio, los arts. 85,85 bis y 85 ter se posicionan exclusivamente desde la más estrecha perspectiva de las modalidades de gestión de los servicios públicos, hoy necesitada de superación, para adecuarlo a las nuevas realidades, pues el fenómeno de la privatización y de la liberalización han 
transformado el concepto clásico subjetivo de servicio público dando paso al servicio universal y a las obligaciones de servicio público. Esta transformación conlleva asimismo un cambio en el papel de la Administración local que ha de tener potestades ordenadoras y de control que han de plasmarse en la Ley.

En el régimen jurídico de la contratación de las sociedades mercantiles públicas hay que diferenciar de una parte, el régimen de los contratos de dichas sociedades con terceros, y de otra parte, el régimen propio de las relaciones entre la sociedad mercantil y la Administración pública matriz que participa en ellas como socio. Entiendo que el régimen jurídico de la contratación de estas entidades ad extra se ha clarificado definitivamente, a lo que ha contribuido poderosamente la jurisprudencia del TJUE que ha ido aquilatando la noción de Organismo de Derecho público a efectos de las Directivas de la contratación pública y hoy por hoy ha dejado claro que no cabe interpretar dicho concepto en el sentido de que los Estados puedan excluir de antemano a las sociedades mercantiles bajo control público, pues ha de estarse a si cumplen los requisitos de: a) que hayan sido creadas para satisfacer específicamente necesidades de interés general que no tengan carácter industrial o mercantil; b) dotadas de personalidad jurídica y c) cuya actividad esté mayoritariamente financiada por el Estado, los entes públicos territoriales u otros organismos de Derecho público, cuya gestión se halle sometida a un control por parte de éstos últimos, o cuyo órgano de administración, de dirección o de vigilancia está compuesto por miembros de los cuales más de la mitad sean nombrados por el Estado, los entes públicos territoriales u otros organismos de Derecho público.

La reforma del TRLCAP por el art. 67 de la Ley 62/2003, de 30 de diciembre, en el art. 2 bajo la rúbrica de adjudicación de determinados contratos de Derecho privado ha consagrado para las sociedades mercantiles públicas que constituyan poderes adjudicadores la teoría de los actos separables, quedando sometidas al TRLCAP en lo relativo a la publicidad, capacidad de las empresas, procedimientos y formas de adjudicación, para los contratos citados, que resultan ser los contratos administrativos típicos según el propio TRLCAP siempre que alcancen las cuantías que señala el precepto. Para el resto de los contratos que celebren estas mismas las sociedades mercantiles públicas -insistimos, siempre que constituyan Organismos de Derecho públicopor mor de la DA Sexta reformada, no se aplica ni siquiera la teoría de los actos separables. Esta opción del legislador tiene asimismo su reflejo procesal pues la nueva DA Décimo Sexta atribuye la competencia para la fiscalización de los "actos separables de los contratos administrativos típicos" a la jurisdicción contencioso administrativa, ampliándose el ámbito de la LJCA. En cambio, el co- 
nocimiento de los restantes contratos celebrados por estas mismas sociedades, no se olvide, en cuanto poderes adjudicadores, corresponde a la jurisdicción ordinaria. Se instaura pues, un sistema de dualidad de jurisdicciones para los actos separables de las sociedades mercantiles públicas cuando sean poderes adjudicadores en función de la clase de contrato y de su cuantía que estimo inapropiado y que crea enorme confusión.

Más complejo es el asunto de las relaciones entre las Administraciones públicas y sus sociedades instrumentales, es decir, las relaciones ad intra, cuestión que remite a la delimitación de la noción de medio propio o instrumental de la Administración y a la definición de los límites de los denominados contratos in house providing o domésticos. Pese a que se trata de un tema todavía no cerrado creo que pueden apuntarse criterios sólidos sobre los que asirse que han avanzado la doctrina, la jurisprudencia comunitaria, así como algunos pronunciamientos de nuestros tribunales.

Pese a gozar de personalidad jurídica diferenciada, y centrados en el ámbito local, la sociedad mercantil local, que constituye un modo directo de gestión, no puede considerarse un tercero a efectos de la Administración local matriz, sino una simple opción organizatoria no desvinculada de la organización de la propia Entidad local. De ahí que no tenga sentido que si una Entidad local crea una sociedad mercantil pública para la gestión de competencias, funciones o servicios municipales se le imponga que se someta a la legislación de contratos, toda vez que ha creado una organización ad hoc para ello. En otras palabras, se trata de un medio propio de la Administración. La relación de instrumentalidad tiene como nota esencial la dependencia de la entidad matriz, por consiguiente, entre la matriz y la instrumental sólo caben relaciones de subordinación, a través de la potestad de dirección, como forma de articular el cumplimiento de fines de la matriz a través de la instrumental. La Administración puede decidir si actúa con medios propios (orgánicos o personificados) o requiere de la colaboración de un tercero para la realización de sus competencias y la consecución del interés general. Lo que sí existe es un derecho subjetivo a que, cuando la Administración decide acudir a la contratación, se produzca la misma con concurrencia y publicidad.

Para que exista contrato es preciso que sea celebrado entre, por una parte, un ente territorial y, por otra, una persona jurídicamente distinta de éste. Sólo puede ser de otra manera en el supuesto de que, a la vez, el ente territorial ejerza sobre la persona de que se trate un control análogo al que ejerce sobre sus propios servicios y esta persona realice la parte esencial de su actividad con el ente o los entes que la controlan. 
Por ende, sólo quedan al margen de la normativa comunitaria de la contratación pública y del TRLCAP los encargos, encomiendas o contratos-programas que celebre una Administración territorial matriz con sus propias entidades o sociedades instrumentales. Quiere decirse que al entablarse dicha relación de dependencia únicamente con la matriz bien de manera directa o indirecta, no puede, por definición, erigirse en medio propio de otra Administración pública que no ejerce influencia alguna sobre el ente instrumental, pues en tal supuesto, siempre que la materia sobre la que verse sea objeto de un contrato de obras, de suministro, de consultoría y asistencia o servicios, cualquiera que sea la denominación que reciba, -encargo, encomienda, contrato-programa o convenio-, existe un verdadero contrato al que es de aplicación preceptiva el TRLCAP. Además, no cabe su elusión por la vía de proclamar en el grupo normativo ad hoc aplicable al ente instrumental, aunque se trate de una ley, que es medio propio de otra u otras Administraciones si realmente no lo es. Este es el requisito que subraya el nuevo apartado 1 del art. 3.1 TRLCAP y que impone la revisión de la configuración como "medio propio" de un número importante de sociedades instrumentales, reconduciéndola a sus justos límites al objeto de acomodarse al Derecho comunitario. 